Provided for non-commercial research and educational use only. Not for reproduction or distribution or commercial use.

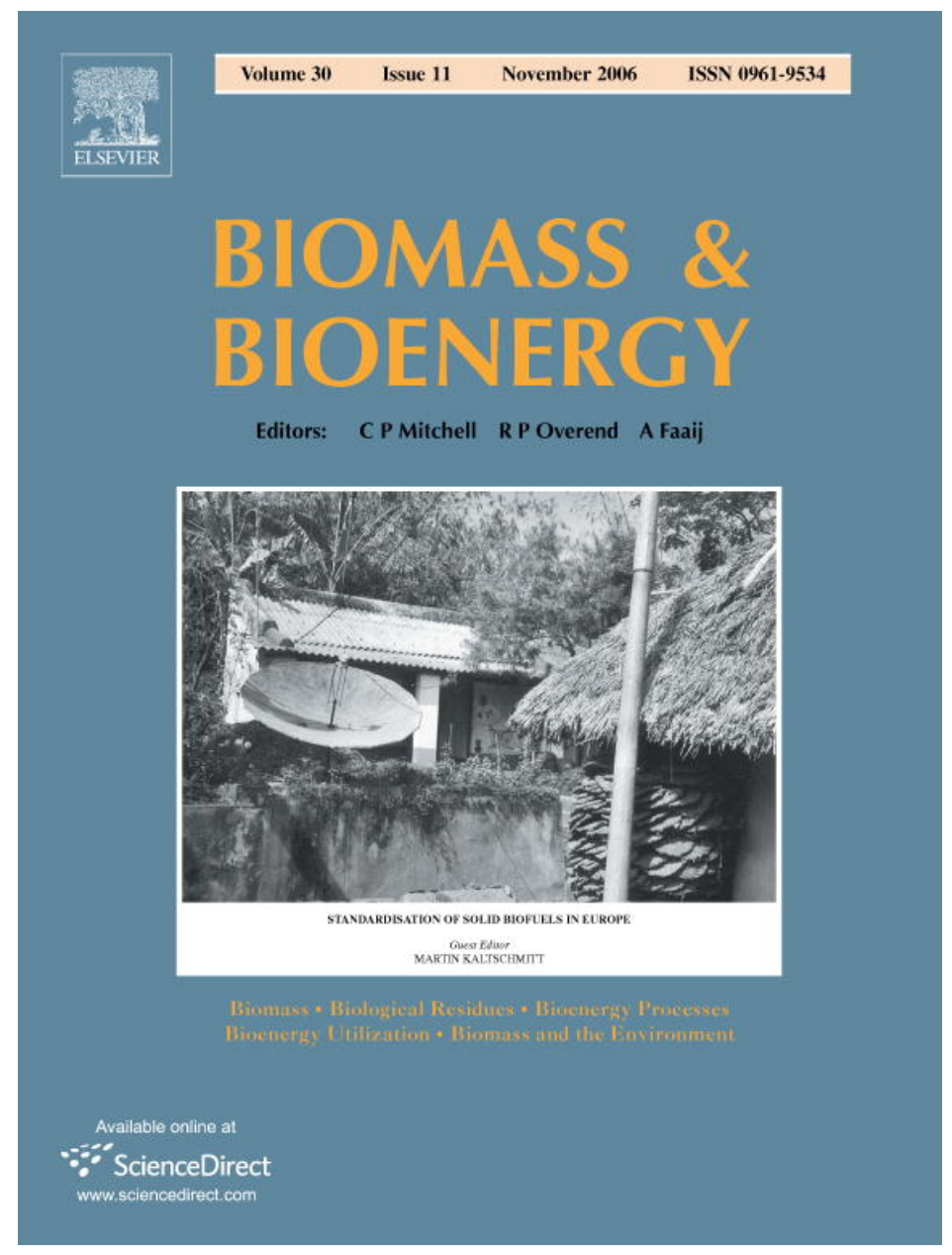

This article was originally published in a journal published by Elsevier, and the attached copy is provided by Elsevier for the author's benefit and for the benefit of the author's institution, for non-commercial research and educational use including without limitation use in instruction at your institution, sending it to specific colleagues that you know, and providing a copy to your institution's administrator.

All other uses, reproduction and distribution, including without limitation commercial reprints, selling or licensing copies or access,

or posting on open internet sites, your personal or institution's website or repository, are prohibited. For exceptions, permission may be sought for such use through Elsevier's permissions site at: 


\title{
Particle density determination of pellets and briquettes
}

\author{
Fabienne Rabier ${ }^{\mathrm{a}, *}$, Michaël Temmerman ${ }^{\mathrm{a}}$, Thorsten Böhm ${ }^{\mathrm{b}}$, Hans Hartmann ${ }^{\mathrm{b}}$, \\ Peter Daugbjerg Jensen ${ }^{\mathrm{c}}$, Josef Rathbauer ${ }^{\mathrm{d}}$, Juan Carrasco ${ }^{\mathrm{e}}$, Miguel Fernández ${ }^{\mathrm{e}}$ \\ ${ }^{a}$ Centre wallon de Recherches agronomiques, Département de Génie rural, CRA-W, Chaussée de Namur, 146, B 5030 Gembloux, Belgium \\ ${ }^{\mathrm{b}}$ Technologie und Förderzentrum für Nachwachsende Rohstoffe, TFZ, Schulgasse 18, D 94315 Straubing, Germany \\ ${ }^{\mathrm{c}}$ Forest and Landscape, The Royal Veterinary and Agricultural University, Rolighedsvej 23, DK 1958 Frederiksberg C, Denmark \\ ${ }^{\mathrm{d}}$ Bundesanstalt für Landtechnik, BLT, Rottenhauer Strasse, 1 A 3250 Wieselburg, Austria

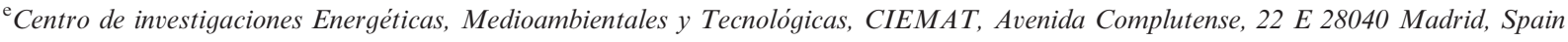

Received 17 November 2005; accepted 9 June 2006

Available online 15 August 2006

\begin{abstract}
Several methods and procedures for the determination of particle density of pellets and briquettes were tested and evaluated. Round robin trials were organized involving five European laboratories, which measured the particle densities of 15 pellet and five briquette types. The test included stereometric methods, methods based on liquid displacement (hydrostatic and buoyancy) applying different procedures and one method based on solid displacement.

From the results for both pellets and briquettes, it became clear that the application of a method based on either liquid or solid displacement (only tested on pellet samples) leads to an improved reproducibility compared to a stereometric method. For both, pellets and briquettes, the variability of measurements strongly depends on the fuel type itself.

For briquettes, the three methods tested based on liquid displacement lead to similar results. A coating of the samples with paraffin did not improve the repeatability and the reproducibility.

Determinations with pellets proved to be most reliable when the buoyancy method was applied using a wetting agent to reduce surface tensions without sample coating. This method gave the best values for repeatability and reproducibility, thus less replications are required to reach a given accuracy level. For wood pellets, the method based on solid displacement gave better values of repeatability, however, this instrument was tested at only one laboratory.
\end{abstract}

(C) 2006 Elsevier Ltd. All rights reserved.

Keywords: Particle density; Pellets; Briquettes; Liquid displacement; Solid displacement; Stereometry

\section{Introduction}

Several national standards [1-3] describe the particle density of pellets and briquettes as a quality indicator of densified fuels. It is also defined as quality parameter for briquettes in the technical specifications $\mathrm{prCEN} / \mathrm{TC}$ 14961 [9].

Moreover, this property has an influence on bulk density and on combustion properties of pellets and briquettes (heat conductivity, burning time and rate of degasification) $[4,5,11]$. The determination of this parameter, which is

\footnotetext{
${ }^{*}$ Corresponding author. Tel.: + 3281627169 ; fax: + 3281615847 .

E-mail address: rabier@cra.wallonie.be (F. Rabier).
}

defined as ratio of the mass and the volume of a sample including pore volume, faces several difficulties. While mass measurements are easy to realise, the volume determination is connected with several uncertainties. Irregular particle shapes and surface roughness increase the result variability, particularly for stereometric methods. Moreover, the hygroscopic properties of compressed wood fuels, which seem to depend on the type of raw material [6] introduce incertainties for the volume estimation by liquid displacement methods. These are mostly due to the liquid penetration into the compressed fuel, the bonding forces and the dissolving of the fuel's shape. Finally, the hygroscopic properties of pellets and briquettes not only act on the mass of the sample but also influence its volume [5]. 
This paper aims at comparing different methods for the estimation of the particle density of pellets and briquettes. It focuses on stereometric methods and determinations applying liquid and solid displacement. These methods have been tested in an international round robin by five different European laboratories using 15 pellet and five briquette types.

\section{Material and methods}

\subsection{Pellets sample selection}

The 15 selected pellet types (Table 1) were produced in five different European countries and were all commercially available. The selection includes wood pellets with different diameter and pellets made from agricultural residues. The moisture contents of the pellets were between $6 \%$ and $10 \%$ (w.b.).

\subsection{Briquettes sample selection}

The five briquettes selected were produced in four different European countries and were all commercially available. Their origin, production process, shape and raw material are listed in Table 2. As for pellets, the moisture content was measured before testing. The moisture contents of all briquettes were below $10 \%$ (w.b.).

\subsection{Tested methods}

Particle density is calculated as the ratio of the mass to the sample volume including pore volume. Even though the moisture content seems to have an influence on the particle density [7], in this study, the increase of the volume, depending on the moisture content, is neglected. The particle density is thus expressed for moisture contents as "as received". All participating laboratories followed

Table 1

Description of the different pellet types selected for testing

\begin{tabular}{lll}
\hline Pellets code & Diameter $(\mathrm{mm})$ & Raw material \\
\hline P1 & 6 & Mixed wood \\
P2 & 6 & Softwood \\
P3 & 6 & Hardwood \\
P4 & 6 & Hardwood \\
P5 & 8 & Mixed wood \\
P6 & 8 & Mixed wood \\
P7 & 8 & Mixed wood \\
P8 & 6 & Mixed wood \\
P9 & 6 & Mixed wood \\
P10 & 9 & Straw \\
P11 & 6 & Miscanthus \\
P12 & 6 & Softwood \\
P13 & 6 & Softwood \\
P14 & 8 & Hay \\
P15 & 9 & Straw \\
\hline
\end{tabular}

Table 2

Description of the different briquette types selected for testing

\begin{tabular}{llll}
\hline $\begin{array}{l}\text { Briquette code } \\
\text { (Origin) }\end{array}$ & $\begin{array}{l}\text { Production } \\
\text { press }\end{array}$ & $\begin{array}{l}\text { Cross } \\
\text { section }\end{array}$ \\
\hline B1 (France) & Extruder & Hexagonal & $\begin{array}{l}\text { Raw } \\
\text { material }\end{array}$ \\
B2 (Germany) & Extruder & Square & Mixed wood \\
B4 (Spain) & Piston & Circular & Rectangular \\
B5 (Austria) & Piston & Circular & Mixed wood
\end{tabular}

Table 3

Particle density: tested methods and number of laboratories involved for briquettes and pellets

\begin{tabular}{|c|c|c|}
\hline Tested methods & $\begin{array}{l}\text { Number of } \\
\text { laboratories } \\
\text { involved in } \\
\text { briquette testing }\end{array}$ & $\begin{array}{l}\text { Number of } \\
\text { laboratories } \\
\text { involved in pellet } \\
\text { testing }\end{array}$ \\
\hline Stereometry $1^{\mathrm{a}}$ & 5 & 4 \\
\hline Stereometry $2^{\mathrm{b}}$ & 3 & Not tested \\
\hline $\begin{array}{l}\text { Hydrostatic and paraffin } \\
\text { coating }\end{array}$ & 4 & 4 \\
\hline Hydrostatic and wetting agent & Not tested & 3 \\
\hline $\begin{array}{l}\text { Buoyancy without paraffin } \\
\text { coating }\end{array}$ & 2 & Not tested \\
\hline $\begin{array}{l}\text { Buoyancy and paraffin } \\
\text { coating }\end{array}$ & 4 & 4 \\
\hline Buoyancy and wetting agent & Not tested & 3 \\
\hline Solid displacement method & Not tested & 1 \\
\hline
\end{tabular}

${ }^{\text {a }}$ Stereometrical cross-section calculation.

${ }^{\mathrm{b}}$ Cross-section calculation by cut out paper.

the same guidelines, which had jointly been elaborated in order to exclude effects caused by inconsistent handling procedures.

Table 3 shows the tested methods and the number of laboratories involved in the round robin trials. Each participating laboratory performed 15 replications for each tested fuel and each tested method.

\subsubsection{Liquid displacement methods}

Liquid displacement methods are based on the Archimedes principle. The volume of a sample is estimated by the mass of the volume that is displaced while the sample is submerged in liquid. However, those methods have two major disadvantages. First, due to hygroscopic fuel properties, liquid may be absorbed. Second, air bubbles may build up on the sample surface while submerged due to surface tension. In order to avoid the impact of these 
disadvantages, samples may be coated, e.g. with paraffin, while the addition of wetting agents is used to reduce surface tension.

The tests on liquid displacement methods were performed in pure water, (on paraffin-coated or non-coated samples) and in a mix of water and wetting agent (for noncoated samples). The applied paraffin had a melting point between 52 and $54{ }^{\circ} \mathrm{C}$. The added wetting agent was tOctylphenoxypolyethoxyethanol; polyethylene glycol tertoctylphenyl ether (CAS number: 9002-93-1; trade mark Triton X-100), at a concentration in water of $1.5 \mathrm{~g} / 1$.

The pellet sample, between 4 and $8 \mathrm{~g}$, was weighed to the nearest $0.0001 \mathrm{~g}$ while the briquette sample (each single briquette) was weighed to the nearest $0.1 \mathrm{~g}$.

For the volume calculation, the density changes of the liquid caused by different temperatures, was taken into account.

2.3.1.1. The hydrostatic method. In the hydrostatic method, the mass of the liquid which is displaced by the sample was determined. A glass beaker filled with liquid (water or mix of water and wetting agent) was placed on the weighing platform of a balance. The sample material was placed in a cage that was fixed at a vertically moving arm of a tripod.

The liftable arm realised the submergence of the sample filled cage, which should have no physical contact with the beaker glass when under water (Fig. 1). The mass difference between the empty system and the system with a sample placed in the cage allows the volume determination of the sample and the calculation of the particle

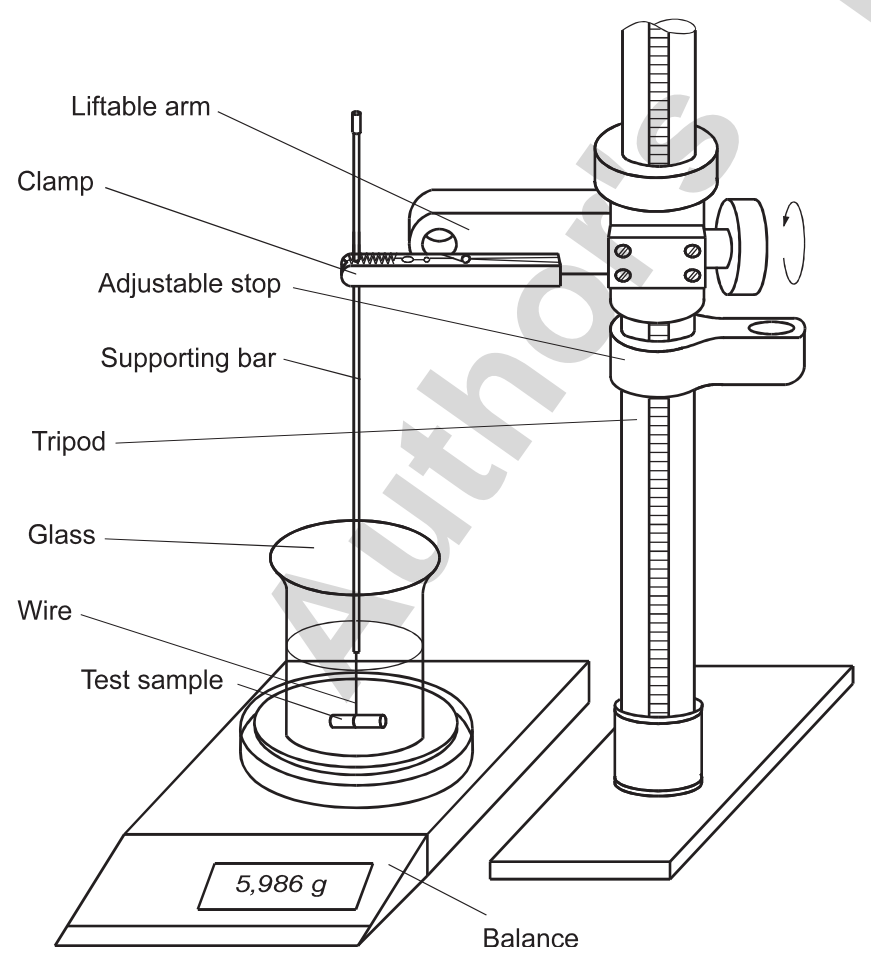

Fig. 1. Volume determination with the hydrostatic method [4]. density $\left(\rho_{\mathrm{u}}\right)$ according to Eq (1)

$\rho_{\mu}=\frac{m \mathrm{u}}{m_{\mathrm{w} . \mathrm{dis}}} \rho_{\mathrm{w}}$,

where $\rho_{\mathrm{w}}$ is the density of liquid at a given temperature, $m_{\mathrm{u}}$ is the weight of the test sample in air and $m_{\mathrm{w} . d i s}$ is the weight of liquid displaced by the test sample.

2.3.1.2. The buoyancy method. In the buoyancy method, the apparent weight of the sample during submergence is determined, the buoyancy is the difference between the sample's weight in air and its apparent weight in liquid. In contrast to the hydrostatic method, the weighing platform is not loaded with a liquid container. For briquette volume determination, the liquid container was positioned underneath a balance, which was equipped with a below-balance weighing hanger (Fig. 2). Pellet testing was conducted by the use of a particle density determination kit provided for the balance by the manufacturer (Fig. 3). The kit provides a bridge for the weighing plate where the beaker glass was placed on the bridge in order to prevent any direct load on the weighing plate. The sample volume was determined by the difference between the mass of a sample in air and the mass of the same sample submerged in the liquid. The particle density $\left(\rho_{\mathrm{u}}\right)$ of the sample is calculated according to Eq. (2).

$\rho_{\mu}=\frac{m \mathrm{u}}{m_{\mathrm{u}}-m_{\mathrm{s}}} \rho_{\mathrm{w}}$,

where $\rho_{\mathrm{w}}$ is the density of liquid at a given temperature, $m_{\mathrm{u}}$ is the weight of the test sample in air and $m_{\mathrm{s}}$ is the weight of the sample in liquid.

2.3.1.3. Paraffin coating. The paraffin coatings were been performed by immersing the sample in a bath of liquid paraffin (temperature: $100^{\circ} \mathrm{C}$ ). Samples were weighed before and after the paraffin coating, in order to calculate

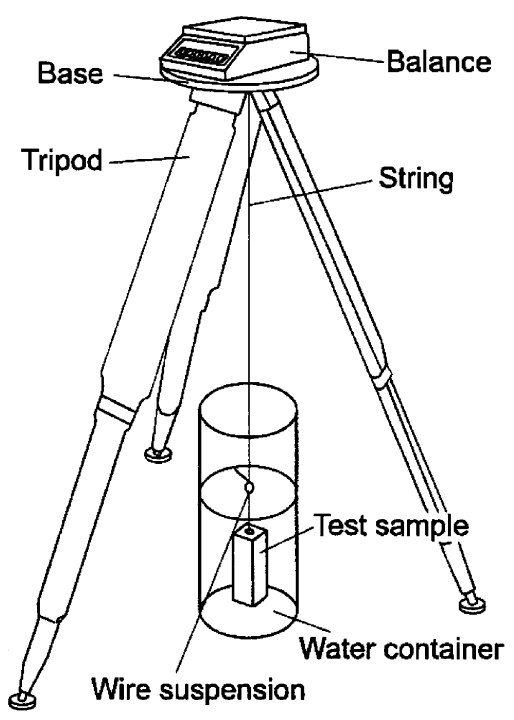

Fig. 2. Volume determination with the buoyancy method (measurement by the bottom of a balance). 


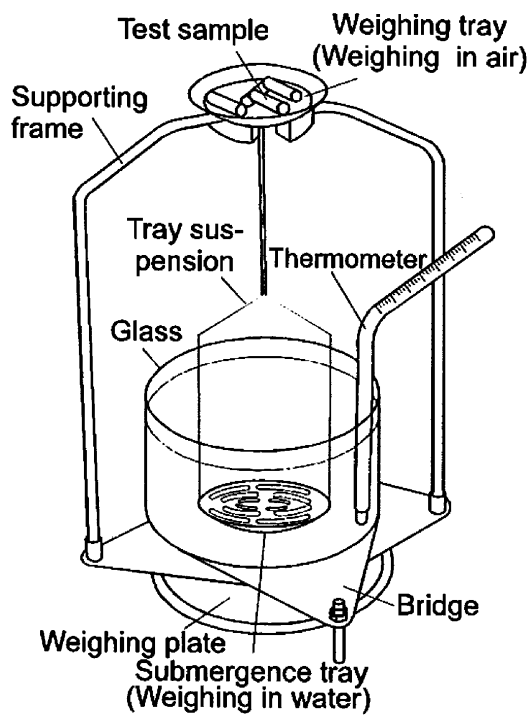

Fig. 3. Volume determination with the buoyancy method (kit [4]).

the mass of the applied paraffin. The paraffin density was $900 \mathrm{~g} / 1$.

\subsubsection{Stereometric methods}

Stereometric methods are based on the measurement of the dimensions (e.g. diameter, length, width, height) of a single regularly shaped particle using length-measuring instruments (e.g. calliper gauge, rule). The volume of the sample is then determined by calculating the volume of the nearest regular geometrical shape (cylinder, cuboid, cube).

2.3.2.1. Stereometric measurements on pellets. A single pellet sample was weighed to the nearest $0.0001 \mathrm{~g}$. All size measurements were made at a precision of $0.1 \mathrm{~mm}$. In the calculation the pellet was considered to have the shape of a cylinder.

The convex or concave endings of each pellet were removed perpendicularly to the axis of the pellet. The extremities were cut and sanded in order to obtain smooth sides. The length of the pellet was then measured twice (measures were taken at the right angle of each other). The diameter was measured six times, twice at each end and twice in the middle of the pellet; between two successive measurements the pellet was always rotated by $90^{\circ}$.

\subsubsection{Stereometric measurements on briquettes. A sin-} gle briquette sample was weighted to the nearest $0.1 \mathrm{~g}$. All the measures were made at a precision of $0.1 \mathrm{~mm}$. The irregular sides of each single briquette were removed, the extremities were cut by a blade or a band saw at a right angle to the axis of the briquette.

The length of each briquette was determined twice by a calliper gauge (precision $0.1 \mathrm{~mm}$ ). Where the briquette had a central hole, the diameter if this hole was measured (twice, perpendicular, at each ending) and the hole volume was subtracted from the total volume.
For the calculation of the briquette's cross-section two different approaches were applied. As done for pellets, the first approach was based on measuring the three dimensions of the briquette and to estimate its volume by using geometric formulaes. The second approach aimed at estimating the surface of the briquette's cross-section by the use of a paper sheet of known dimensions. The sheet was weighed (to the nearest $0.0001 \mathrm{~g}$ ), afterwards the briquette was placed on the paper in such a way that the contour of the briquette could be drawn on the paper. Finally, the briquette's cross-section was precisely cut by a pair of scissors and weighed. The mass relation between the cut piece of paper and the original sheet mass enabled the calculation of the cross-section area of the briquette. This cross-section was then multiplied by the length of the sample in order to estimate its volume.

\subsubsection{Solid displacement method}

A commercially available powder pycnometer (GeoPyc 1360 by Micromeritics, USA Fig. 4) was used. In this method the apparent volume is determined by the displacement of a powder ("DryFlo"). At first an empty measurement is made without any sample in order to measure the initial volume of the powder. A plunger is moved step by step until a predefined consolidation force is reached; here the position of the plunger in the cylinder is recorded. Then the actual measurement was performed by adding the sample into the cylinder and repeating the same procedure as for the blank test using the same consolidation force. The volume was calculated from the difference of the two plunger positions, before and after sample addition. Only one partner tested this equipment and as it is a non-destructive method it was also used to determine the penetration coefficient of paraffin for pellets (see Section 2.4).

\subsection{Analysed parameters}

In order to evaluate the influence of each tested method and each selected fuel on the particle density results, individual and global mean values and standard deviations

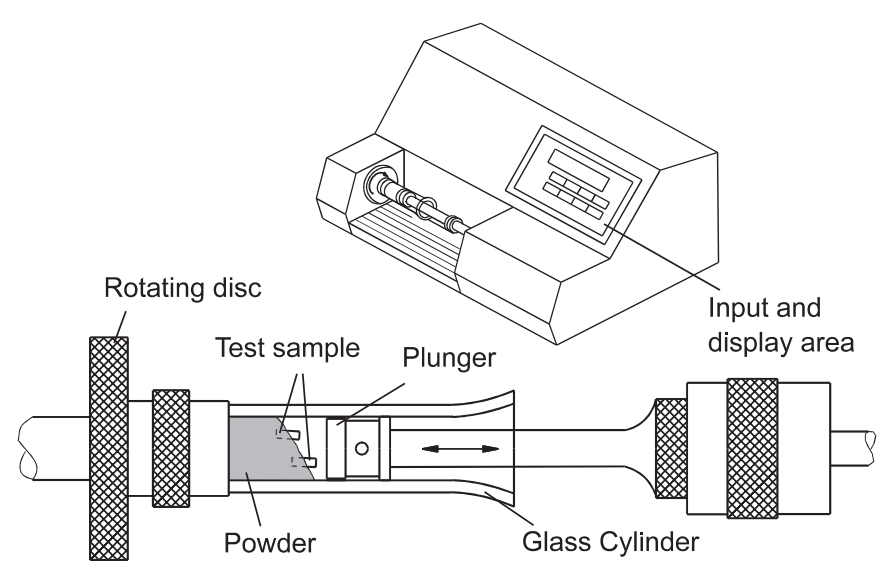

Fig. 4. Volume determination of pellet samples with the displacement of solid method (pycnometer [4]). 
were calculated for the 15 replications at each laboratory and for all participating laboratories. Moreover, the relative and absolute repeatability and reproducibility limits were calculated following the ISO 5725.2 [8]. For pellets, repeatability and reproducibility were calculated for three distinct groups of pellets. A first group consisted of all 15 pellet types tested in the project, a second group consisted of agricultural residue pellets only and a third group consisted of wood pellets only.

The number of replications which are required to ensure several accuracy level of $0.5 \%, 1 ; 2 \%$ or $5 \%$ was determined following a common statistical calculation procedure according to Dagnelie [10], the considered first and second kind errors are, respectively $\alpha=0.05$ and $\beta=0.5$. To compare the mean values of particle density obtained by the different methods, analysis of variances (ANOVA) were conducted with a significance level of $5 \%$.

The comparison of the repeatability and reproducibility limits was made with a $F$-test (test of variance equality of variances with $\alpha=5 \%$ ) [10].

Concerning the paraffin coating different calculations were made in order to evaluate different correction modes for the added volume of the coating. Knowing the mass of applied paraffin and the density of paraffin, the applied volume of paraffin on the sample was determined by calculation.

In the first approach, it was assumed that the total quantity of paraffin remains outside the sample. Therefore, a corrected density (Corr1 density) was calculated by subtracting the calculated volume of paraffin from the measured volume. This calculation was done for briquettes and pellets.

In a second approach (for pellets only), the use of the pycnometer makes it possible to determine the average amount of paraffin which penetrates the sample during preparation (coating). Three of the 15 pellet types were chosen for the measurements (a $6 \mathrm{~mm}$ diameter wood pellet, a $8 \mathrm{~mm}$ diameter wood pellet and a pellet made of agricultural residues). The three samples were measured twice with and without paraffin coating (10 replications each). The comparison between both volumes and the quantity of applied paraffin allowed the share of paraffin penetration for each of the three pellet types to be determined.

These paraffin penetration shares were applied on all tested pellets (according to the raw material and the diameter) to calculate a second corrected density (Corr2 density) by regarding only the paraffin volume, which remains on the pellet's surface. The corrected densities (Corr1 and Corr2) were compared to the non-corrected density ( $\mathrm{Nc}$ density).

\section{Results and discussion for pellet trials}

\subsection{Mean values and standard deviation}

Fig. 5 shows the results and standard deviations of the tested particle density determination methods for 15 pellet types (mean values for all laboratories). Concerning the

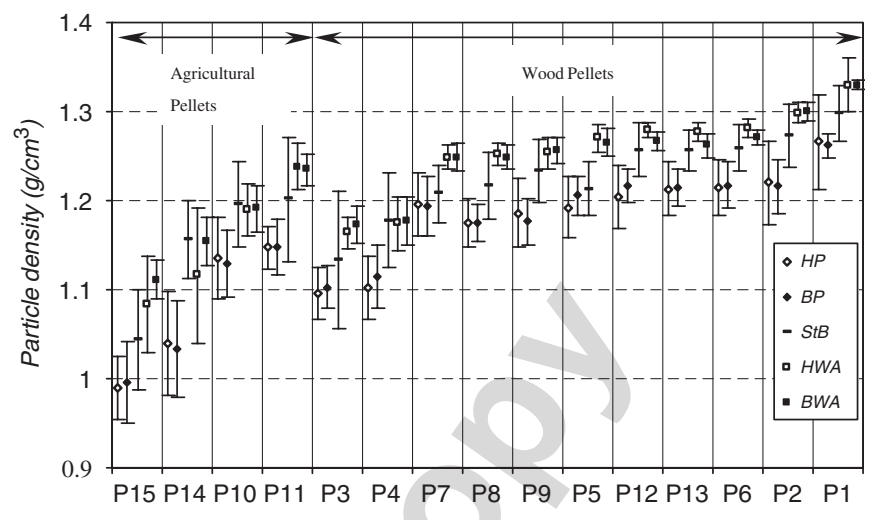

Fig. 5. Particle density of 15 pellet types estimated by 5 different methods (mean value and standard deviation of involved laboratories). HP, hydrostatic with paraffin coating, BP, buoyancy with paraffin coating, $\mathrm{StB}$, stereometric measurements, HWA, buoyancy with wetting agents, BWA, buoyancy with wetting agents.

variability of the results, a tendency depending on the single pellet types is observed. This was confirmed by an ANOVA (two-way ANOVA method and pellet types, fixed model) which shows that the single pellet type has a significant influence and the method has a highly significant influence on the variances.

In fact, the variability is influenced by the value of the particle density itself. Variations are highest for low-density pellets, while they are lowest for high-density pellets. This was confirmed by a ANOVA analysis (two-way analysis: diameter and raw material) on the variances with the density as a co-variable.

For agricultural residues pellets and low-densities wood pellets (density $<1.2 \mathrm{~g} / \mathrm{cm}^{3}$ ), stereometric determinations lead to a higher variability (variance of $0.062\left(\mathrm{~g} / \mathrm{cm}^{3}\right)^{2}$ ) compared to the liquid displacement methods, particularly when the buoyancy method with addition of wetting agent is used (variance of $\left.0.019\left(\mathrm{~g} / \mathrm{cm}^{3}\right)^{2}\right)$.

Concerning wood pellets with higher particle densities, as test of variance equality has showed that methods using wetting agent give equivalent variances $\left(0.028\left(\mathrm{~g} / \mathrm{cm}^{3}\right)^{2}\right)$ which are significantly lower to the ones obtained with the three other methods.

Due to the paraffin coating, densities obtained with methods using paraffin (hydrostatic and buoyancy) are lower than for the other methods.

The comparison between hydrostatic and buoyancy methods with paraffin and wetting agent was made with ANOVA (a two-way variance analysis, methods and partners, fixed model). This analysis has shown that buoyancy and hydrostatic methods - no matter whether paraffin coatings or wetting agents are applied - seem to produce similar results and can therefore be regarded as compatible. It was also found that the influence of the laboratory on the result is highly significant. Additionally an interaction between the laboratory and the method factors was observed which means that for some laboratories the mean values of particle density obtained with both methods can be different. 
As the solid displacement method was only tested by one laboratory the results shown in Fig. 6 are those obtained for this laboratory only. For low-density pellets, the variability of the results obtained with the method based on solid displacement is comparable to the one obtained with the liquid displacement methods. For the wood pellets with higher densities, the variations are smaller.

\subsection{Repeatability, reproducibility limits and number of replications}

Table 4 shows the relative and absolute repeatability and reproducibility limits of the tested particle density determination methods.

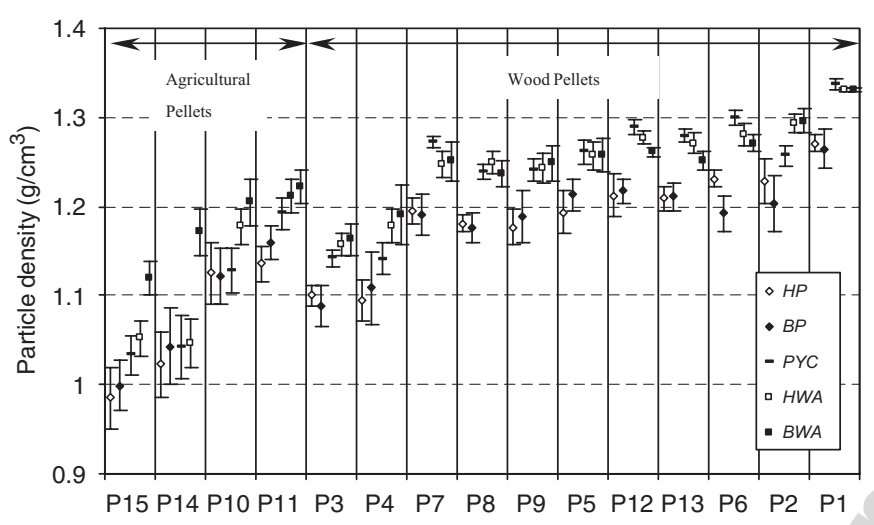

Fig. 6. Particle density of 15 pellet types estimated by 5 different methods (mean value and standard deviation of one laboratory). HP, hydrostatic with paraffin coating, BP, buoyancy with paraffin coating, PYC, solid displacement method, HWA, buoyancy with wetting agents, BWA, buoyancy with wetting agents.
Additionally, the required minimum number of replications which are necessary to obtain a given accuracy level $(0.5 \%, 1 \%, 2 \%$ and $5 \%)$ are given.

The parameters are given for three different groups of pellets: wood pellets, agricultural pellets and all pellets together.

Regarding evaluations of all pellets it is obvious that repeatability limits are higher for stereometric determinations $(8.7 \%)$ and displacement methods with paraffin coatings $(7.1 \%$ for hydrostatic and $6.1 \%$ for buoyancy) compared to immersion methods where wetting agents are added (4.9\% for hydrostatic and 3.5\% for buoyancy).

The advantages of the wetting agents method was also confirmed when the laboratory influence is considered (reproducibility limits $R$ ), at least this applied for wood pellets. However, for agricultural pellets only the buoyancy method applying wetting agents seems also to result in better reproducibility.

It has to be added that the pellet raw material influences the repeatability and the reproducibility. Pellets from agricultural residues show worse results than wood pellets. The group made of agricultural pellets showed $r \%$ ranging from 4.56 to $11.55 \%$ depending on the method, while repeatabilities were between $2.19 \%$ and $7.66 \%$ for wood pellets.

The buoyancy method applying wetting agents requires the least replications to achieve a given accuracy level. For example, to secure an accuracy level of $2 \%$, only 8 replications are needed for wood pellets, while 71 replications are necessary for the stereometric method.

It also appears that it is difficult to achieve accuracy below $1 \%$ for the whole range of materials. In fact, even

Table 4

Particle density determination of pellets: relative $(r \%)$ and absolute $(r)$ repeatability (mean value through laboratories), relative $(R \%)$ and absolute $(R)$ reproducibility limits and the required number of replications $(n)$ to reach a certain accuracy level

\begin{tabular}{|c|c|c|c|c|c|c|c|c|c|}
\hline \multirow[t]{2}{*}{ Pellets } & \multirow[t]{2}{*}{ Method } & \multirow[t]{2}{*}{$r\left(\mathrm{~g} / \mathrm{cm}^{3}\right)$} & \multirow[t]{2}{*}{$r(\%)$} & \multirow[t]{2}{*}{$R\left(\mathrm{~g} / \mathrm{cm}^{3}\right)$} & \multirow[t]{2}{*}{$R(\%)$} & \multicolumn{4}{|l|}{$n$} \\
\hline & & & & & & $0.5 \%$ & $1 \%$ & $2 \%$ & $5 \%$ \\
\hline \multirow[t]{5}{*}{ Wood pellets } & St & 0.09 & 7.66 & 0.12 & 9.36 & 1137 & 284 & 71 & 11 \\
\hline & HP & 0.08 & 6.52 & 0.11 & 9.59 & 315 & 79 & 20 & 3 \\
\hline & HWA & 0.04 & 3.52 & 0.05 & 4.13 & 240 & 60 & 15 & 2 \\
\hline & $\mathrm{BP}$ & 0.07 & 5.60 & 0.08 & 6.75 & 124 & 31 & 8 & 1 \\
\hline & $\mathrm{BW}$ & 0.04 & 2.91 & 0.04 & 3.47 & 127 & 32 & 8 & 1 \\
\hline \multirow{5}{*}{$\begin{array}{l}\text { Agricultural residues } \\
\text { pellets }\end{array}$} & $\mathrm{St}$ & 0.13 & 11.55 & 0.16 & 13.85 & 644 & 161 & 40 & 6 \\
\hline & HP & 0.10 & 8.89 & 0.12 & 11.44 & 417 & 104 & 26 & 4 \\
\hline & HWA & 0.09 & 7.51 & 0.16 & 13.59 & 391 & 98 & 24 & 4 \\
\hline & BP & 0.09 & 9.00 & 0.12 & 11.64 & 367 & 92 & 23 & 4 \\
\hline & BWA & 0.05 & 4.56 & 0.07 & 6.33 & 79 & 20 & 5 & 1 \\
\hline \multirow[t]{5}{*}{ All pellets } & St & 0.11 & 8.73 & 0.13 & 10.63 & 1137 & 284 & 71 & 11 \\
\hline & $\mathrm{HP}$ & 0.08 & 7.12 & 0.12 & 10.04 & 417 & 104 & 26 & 4 \\
\hline & HWA & 0.06 & 4.90 & 0.10 & 7.80 & 391 & 98 & 24 & 4 \\
\hline & $\mathrm{BP}$ & 0.07 & 6.10 & 0.09 & 7.75 & 367 & 92 & 23 & 4 \\
\hline & BWA & 0.04 & 3.46 & 0.05 & 4.40 & 127 & 32 & 8 & 1 \\
\hline
\end{tabular}

HP hydrostatic with paraffin coating, BP buoyancy with paraffin coating, StB stereometric measurements, HWA buoyancy with wetting agents, BWA buoyancy with wetting agents. 
when applying the buoyancy method with wetting agent, 32 replications would be required to meet the $1 \%$ accuracy demand considering all the pellet types.

However the data presented here are calculated for the most variable pellet types, when variability is lower, e.g. for pellet type P1, the minimum number of replications can be much lower. Then, for example, only two replications would be enough to obtain a precision of $0.5 \%$ when using buoyancy with wetting agent method on pellet type P1.

Concerning the method based on solid displacement, Table 5 shows the relative $\left(\begin{array}{ll}r & \%\end{array}\right)$ and absolute $(r)$ repeatability limits obtained by the single laboratory where the tests were made. These results are compared to the buoyancy with wetting agent method.

The method using the powder pycnometer shows a better repeatability for the wood pellets than the buoyancy with wetting agent method $(2.34 \%$ and $3.88 \%$, respectively), which results in a lower required number of replication. To reach $1 \%$ accuracy only nine replications are needed instead of 32 using the buoyancy method with addition of wetting agent.

\subsection{Correction of coating volume}

The global mean value of the applied paraffin share (in relation to the total sample weight) is $8.9 \%$ in average (through laboratories and pellet types). The share of the applied paraffin on the different pellet types vary from $4 \%$ to $22 \%$. The variability between the participating laboratories is important with calculated coefficients of variation ranging between $14 \%$ and $37 \%$.

The calculated shares of paraffin penetration for the 3 pellets type was: $68 \%$ for pellets made from agricultural residues, $36 \%$ for $6 \mathrm{~mm}$ wood pellets, and $26 \%$ for $8 \mathrm{~mm}$ wood pellets. Those penetration shares, which are particularly high for agricultural pellets, show that it is not acceptable to assume that the applied paraffin does not

Table 5

Particle density determination of pellets: relative $(r \%)$ and absolute $(r)$ repeatability (mean value through laboratories) and the required number of replications $(n)$ to reach a certain accuracy level

\begin{tabular}{lllllllll}
\hline Pellets & Method & \multirow{2}{*}{$\left(\mathrm{g} / \mathrm{cm}^{3}\right)$} & $r(\%)$ & $n$ & & & \\
\cline { 5 - 9 } & & & & & $0.5 \%$ & $1 \%$ & $2 \%$ & $5 \%$ \\
\hline Wood pellets & PYC & 0.03 & 2.34 & 38 & 9 & 2 & 1 \\
& BWA & 0.05 & 3.88 & 127 & 32 & 8 & 1 \\
$\begin{array}{l}\text { Agricultural } \\
\text { residues } \\
\text { pellets }\end{array}$ & PYC & 0.07 & 6.70 & 186 & 47 & 12 & 2 \\
& & & & & & & \\
All pellets & BWA & 0.06 & 5.38 & 73 & 18 & 5 & 1 \\
& PYC & 0.05 & 3.66 & 186 & 47 & 12 & 2 \\
& BWA & 0.05 & 4.29 & 127 & 32 & 8 & 1 \\
\hline
\end{tabular}

PYC solid displacement, BWA buoyancy with wetting agents.

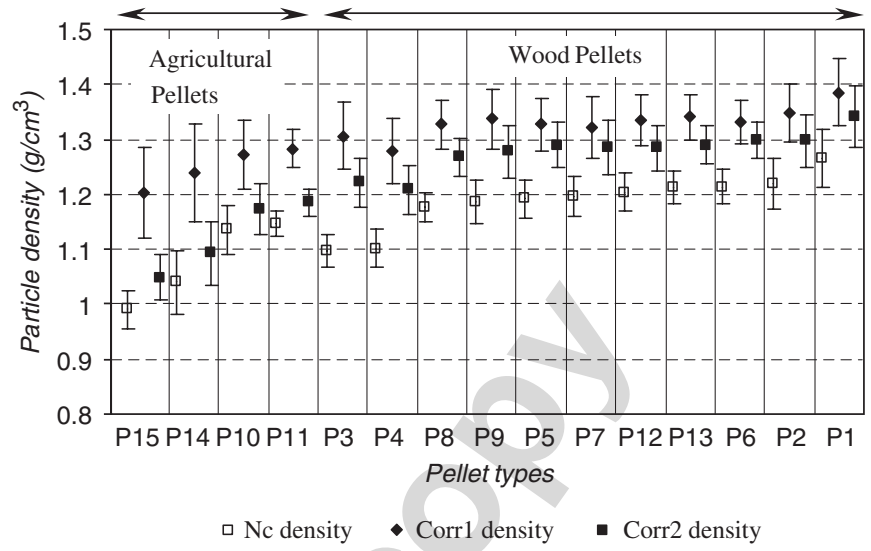

Fig. 7. Non-corrected density (Nc density) and corrected densities (Corrl and Corr 2 densities), mean value and standard deviation, depending on the pellet types obtained with the hydrostatic with paraffin coating method.

penetrate the sample. Penetration probably depends on the particle density of the fuel itself but it is difficult to extrapolate as the calculation was only done for three pellet types. As explained in Section 2.4 those penetration shares were used to calculate the Corr2 density.

Fig. 7 shows the three densities for the hydrostatic method with paraffin coating, similar tendencies were observed for the buoyancy method. Particle density measurements where the volume of the paraffin coating is subtracted from the measured volume (Corrl and Corr2) are higher than Nc densities. The reason is obvious as the measured volume is reduced, consequently particle density increases. Corr 1 density is always superior to Corr2 density because, for Corr2, a lower paraffin volume is subtracted from the total volume since the quantity of paraffin that penetrates the pellet is not considered.

The statistical analysis (one-way analysis of variance, factor: correction) confirms that the three densities differ highly significantly from each other. Additionally, the coefficient of variations of the Corr1 density are also higher than the ones calculated for the two other densities ( $t$-test, $\alpha=0.05 \%$ ).

The introduction of a correction for the volume of applied paraffin does not have a significant influence on repeatability and on reproducibility when the tested wood pellets and the full range of pellets are regarded. In contrast, pellets made from agricultural residues show significantly higher values of reproducibility for Corr 1 density compare to the Nc (Table 6).

The results show that the correction has an important influence either on the value of particle density and, for Corr1, also on the variability of the results obtained amongst laboratories. This is due to the fact that the volume of applied paraffin can be important compare to the initial sample volume and varies from one pellet type to another and also between laboratories. 
Table 6

Absolute $(R)$ and relative $(R \%)$ reproducibility limits of non-corrected density $(\mathrm{Nc})$ and corrected density (Corr1) for hydrostatic and buoyancy measured on pellets made from agricultural residues

\begin{tabular}{|c|c|c|c|c|c|c|c|c|}
\hline \multirow[t]{3}{*}{ Methods } & \multicolumn{4}{|c|}{$R\left(\mathrm{~g} / \mathrm{cm}^{3}\right)$} & \multicolumn{4}{|c|}{$R(\%)$} \\
\hline & \multicolumn{2}{|c|}{ Hydrostatic } & \multicolumn{2}{|c|}{ Buoyancy } & \multicolumn{2}{|c|}{ Hydrostatic } & \multicolumn{2}{|c|}{ Buoyancy } \\
\hline & $\mathrm{Nc}$ & Corr 1 & $\mathrm{Nc}$ & Corr 1 & $\mathrm{Nc}$ & Corr 1 & $\mathrm{Nc}$ & Corr 1 \\
\hline $\begin{array}{l}\text { Agricultural residues } \\
\text { pellets }\end{array}$ & 0.123 & 0.221 & 0.130 & 0.210 & 11.44 & 17.66 & 11.64 & 16.95 \\
\hline
\end{tabular}

\section{Results and discussion for briquette trials}

\subsection{Mean values and standard deviation}

The results of the particle density determination for the five briquettes tested during the round robin test are shown in Fig. 8 (mean values for all laboratories and standard deviations). It seems that the single-briquette type influences the variability of the results. For example, briquettes B5 show higher variability compare to B3 or B4. Briquettes B1 show a higher variability especially for the stereometric methods. This could be due to intrinsic physical properties of the fuel such as the surface roughness and the presence of a central hole. It can also be noticed that stereometric methods lead to more variable results compared to immersion methods.

A two-way ANOVA (methods and laboratories), which was done for each briquette types separately, shows that the two stereometric methods give results which are statistically different for briquettes B1, B3 and B4 and that the influence of the laboratory leads to difference for briquettes B2, B4, B5. No interaction was observed between both parameters. The two-stereometric methods cannot be regarded as equivalent.

The ANOVA also reveals that except for one briquette (B5), methods using samples with paraffin coatings (buoyancy and hydrostatic) do not differ significantly. The influence of the laboratory is significant for four of the tested briquettes (except briquette B3). As for pellets an interaction between both parameters was observed, oneway ANOVA were made (factor: method, fixed model) for each laboratory and the results have shown that for the briquette $\mathrm{B} 5$ all labs have given results which differ significantly between HP and BP methods.

For briquettes B1, B3 and B4 only one lab of the four involved in the tests gave different results. Concerning the briquette type B2, no influence of the method was found. Except for briquette type B5, for practical application it is therefore not relevant which of the methods based on liquid displacement is used.

\subsection{Repeatability, reproducibility and number of replications}

Table 7 shows the relative $(r \%)$ and absolute $(r)$ repeatability (mean value through all laboratories), the

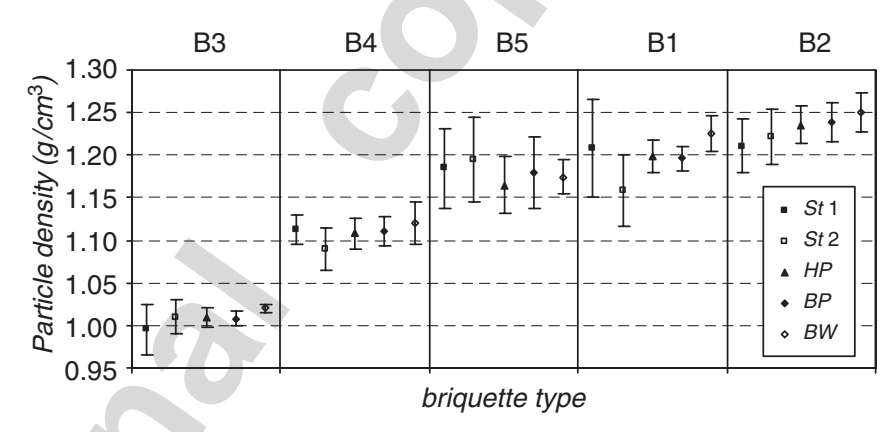

Fig. 8. Particle density of five briquette types estimated by five different methods (mean value and standard deviation of participating laboratories). St1, St2, stereometry 1 and 2, HP, hydrostatic with paraffin coating, BP, buoyancy with paraffin coating, BW, buoyancy without paraffin coating.

relative and absolute reproducibility $(R \%$ and $R)$ of the tested particle density determination methods. Additionally the required minimum number of replications which are necessary to achieve a given accuracy level $(0.5 \%, 1 \%$, $2 \%$ and $5 \%$ ) is given. It is obvious that determinations by immersion methods lead to better repeatabilities and reproducibilities than stereometric measurement. The values of repeatability and reproducibility limits are almost twice as high as for hydrostatic or buoyancy determinations.

It should be mentioned that the reproducibility and repeatability limits calculated for each method clearly depend on the briquette type itself. A test of variance equality $(\alpha=0.05)$ showed that repeatability and reproducibility differ significantly from one briquette to another.

According to Table 7, an accuracy demand of $1 \%$ can only be met by a large number of replications (between 26 and 41 for immersion methods). Compared to other methods the buoyancy method without paraffin coating $(\mathrm{BW})$ is associated with the lowest required number of replications. For example, to guarantee an accuracy level of $2 \%$, seven replications are needed, while 19 are necessary for the stereometry 2 method. However, when variability is lower, e.g. for briquette type $\mathrm{B} 3$, the required number of replications can be much lower.

Then, for example, only four replications would be enough to obtain a precision of $0.5 \%$, when using buoyancy pure water method on briquette type B3. 
Table 7

Particle density determinations of briquettes: relative $(r \%)$ and absolute $(r)$ repeatability (mean value through laboratories) and relative $(R \%)$ and absolute $(R)$ reproducibility

\begin{tabular}{|c|c|c|c|c|c|c|c|c|}
\hline \multirow[t]{2}{*}{ Methods } & \multirow[t]{2}{*}{$R\left(\mathrm{~g} / \mathrm{cm}^{3}\right)$} & \multirow[t]{2}{*}{$r(\%)$} & \multirow[t]{2}{*}{$R\left(\mathrm{~g} / \mathrm{cm}^{3}\right)$} & \multirow[t]{2}{*}{$R(\%)$} & \multicolumn{4}{|l|}{$n$} \\
\hline & & & & & $0.5 \%$ & $1 \%$ & $2 \%$ & $5 \%$ \\
\hline Stereometric measurements 1 & 0.08 & 6.75 & 0.11 & 10.17 & 257 & 64 & 16 & 3 \\
\hline Stereometric measurements 2 & 0.08 & 7.46 & 0.11 & 9.56 & 300 & 75 & 19 & 3 \\
\hline Hydrostatic with paraffin coating & 0.05 & 3.92 & 0.063 & 5.39 & 165 & 41 & 10 & 1 \\
\hline Buoyancy with paraffin coating & 0.05 & 3.99 & 0.069 & 5.91 & 141 & 35 & 9 & 1 \\
\hline Buoyancy without paraffin coating & 0.05 & 4.37 & 0.061 & 5.24 & 105 & 26 & 7 & 1 \\
\hline
\end{tabular}

The required numbers of replications $(n)$ are given for certain accuracy levels.

\subsection{Correction of coating volume}

In average the mass share of the paraffin coating was only $1.8 \%$ of the total sample weight. Compared to pellets, the variations between briquette types and laboratories are relatively small with values ranging from $1.2 \%$ to $2.7 \%$.

As already explained for pellets, the corrected densities are always higher than Nc densities (Table 8). For each type of briquette, the mean values of corrected and $\mathrm{Nc}$ densities were statistically different (ANOVA one-way analysis, factor: correction). A $t$-test $(\alpha=0.05 \%)$ showed that the measuring deviations are equal for both methods of calculation (similar coefficients of variation).

Concerning the values of repeatability and reproducibility calculated for $\mathrm{Nc}$ and corrected densities, it appears that the introduction of a correction for the volume of applied paraffin does not have a significant influence. This is due to the relatively small volume of the paraffin compared to the total briquette volume.

\section{Conclusions}

\subsection{Particle density determination of pellets}

For all methods tested, it appears that the pellet type, linked to the level of particle density, influences the variability of the results.

Generally, the stereometric method is less favourable due to higher variability compared to the liquid displacement methods.

Buoyancy and hydrostatic methods (no matter whether paraffin coatings or wetting agents are applied) produce similar results. For practical application, both methods can be regarded as compatible. Within the group of the liquid displacement methods, considering all pellet types, the buoyancy method using non-coated samples and wetting agent mixed with water performed better in terms of repeatability and reproducibility. This method also needs fewer replications to fulfil a given accuracy level.

The tested solid displacement method also performed well in terms of repeatability particularly for wood pellets, but as this method was applied by only one of the laboratories, further confirmation is required.
Table 8

Mean values, standard deviation (Std) and coefficient of variation (CV \%) for the non-corrected $(\mathrm{Nc})$ density and corrected density (Corr1) for hydrostatic and buoyancy methods for the particle density of briquettes

\begin{tabular}{|c|c|c|c|c|c|}
\hline \multirow[t]{2}{*}{$\begin{array}{l}\text { Briquette } \\
\text { code }\end{array}$} & & \multicolumn{2}{|c|}{$\begin{array}{l}\text { Hydrostatic } \\
\text { method }\left(\mathrm{g} / \mathrm{cm}^{3}\right)\end{array}$} & \multicolumn{2}{|c|}{$\begin{array}{l}\text { Buoyancy method } \\
\left(\mathrm{g} / \mathrm{cm}^{3}\right)\end{array}$} \\
\hline & & $\mathrm{Nc}$ & Corr1 & $\mathrm{Nc}$ & Corr1 \\
\hline \multirow[t]{3}{*}{ B5 } & Mean & 1.165 & 1.193 & 1.180 & 1.205 \\
\hline & Std & 0.033 & 0.032 & 0.042 & 0.040 \\
\hline & $\mathrm{CV} \%$ & 2.8 & 2.7 & 3.5 & 3.3 \\
\hline \multirow[t]{6}{*}{ B4 } & Mean & 1.108 & 1.129 & 1.110 & 1.128 \\
\hline & Std & 0.018 & 0.017 & 0.017 & 0.018 \\
\hline & $\mathrm{CV} \%$ & 1.6 & 1.5 & 1.5 & 1.6 \\
\hline & Mean & 1.198 & 1.237 & 1.196 & 1.235 \\
\hline & Std & 0.019 & 0.021 & 0.015 & 0.014 \\
\hline & $\mathrm{CV} \%$ & 1.6 & 1.7 & 1.3 & 1.1 \\
\hline \multirow[t]{3}{*}{ B2 } & Mean & 1.235 & 1.263 & 1.239 & 1.267 \\
\hline & Std & 0.022 & 0.020 & 0.023 & 0.021 \\
\hline & $\mathrm{CV} \%$ & 1.8 & 1.6 & 1.8 & 1.6 \\
\hline \multirow[t]{3}{*}{ B3 } & Mean & 1.009 & 1.027 & 1.008 & 1.026 \\
\hline & Std & 0.011 & 0.012 & 0.009 & 0.011 \\
\hline & $\mathrm{CV} \%$ & 1.1 & 1.2 & 0.9 & 1.1 \\
\hline
\end{tabular}

If coating of pellets by paraffin is applied before submersion in liquid, a correction for paraffin penetrating the sample is required. A simple assumption of all paraffin remaining outside of the pellet is unacceptable. The use of differentiated correction factors derived from measurements with the solid displacement method (powder pycnometer) is possible. However, due to the increased efforts for the paraffin treatment without any improved precision compared to the uncoated samples, this procedure seems less favourable.

\subsection{Particle density determination of briquettes}

Similar to the observations with pellets, the accuracy and precision of the measurements for briquettes depend on the briquette type too, and the stereomettric method is again less favourable compared to the liquid displacement methods. Both stereometric methods lead to higher variability, higher values of repeatability and reproducibility and need more replications to reach a given accuracy. 
For both, accuracy and practical reasons, the liquid displacement methods seem suitable to become a standard laboratory. For the buoyancy method a balance is required which allows weighing by the use of a bottom hitch to connect the hanging sample material. If no paraffin coating is applied the sample preparation time is low but the water has to be changed often due to briquette disintegration (sometimes after each replication). However, as the coating of the sample surface does not reduce the variability of the results, the efforts of paraffin coating can be abandoned.

For both, pellets and briquettes, it can be stated that an accuracy level better than $1 \%$ can hardly be achieved, for the methods tested. Indeed, over this limit, the number of repetitions needed is far too high for field measurement.

\section{Acknowledgements}

The research was conducted within the European project "Pre-normative work on sampling and testing of solid biofuels for the development of quality assurance systems" (BioNorm) ENK6-CT-2001-00556.

\section{References}

[1] DIN 51731. Testing of solid fuels - compressed untreated woodrequirements and testing. Deutsches Institut für Normung (DIN), Beuth Verlag GmbH. 1996.
[2] ÖNORM M7135. Compressed wood or compressed bark in natural state - pellets and briquettes - requirements and test specifications. Österreichisches Normungsinstitut (ON). 2000.

[3] ASAE 269.4. Cubes, pellets and crumbles - Definitions and methods for determining density, durability and moisture content. The Society for Engineering in Agriculture, Food and Biological Systems (ASAE). 1996.

[4] Böhm T, Hartmann H. Measuring particle density of wood pellets. In: Proceedings of the second world conference and technology exhibition on biomass for energy, industry and climate protection, Rome, Italy.10-14 May 2004.

[5] Lequeux P, Carré J, Hébert J, Lacrosse L, Schenkel Y. Energie et biomasse, la densification. Les presses agronomiques de Gembloux. 1990. 188p.

[6] Lehtikangas P. Storage effects on pelletised sawdust, logging residues and bark. Biomass and Bioenergy 2000;19(5):287-93.

[7] Carré J, Hebert J, Lacrosse L. Critical analysis of the dry process improvement of ligneous materials for energy-producing purposes. Final Report (CEC-ADE/958/83-BDF/1), Centre de Recherches Agronomiques de l'Etat (CRA) Gembloux, 1983; 245p.

[8] ISO 5725.2. Exactitude (justesse et fidélité) des résultats et méthodes de mesure; partie 2: méthodes de base pour la détermination de la répétabilité et de la reproductibilité d'une méthode de mesure normalisée. 1994.

[9] Technical Specification prCEN/TC 14961: Solid biofuel-fuel specification and classes. 2004. 40p.

[10] Dagnelie P. Théorie et méthodes statistiques volume 1 et 2. Presses agronomiques de Gembloux. 1975.

[11] Obernberger I, Thek G. Physical characterisation and chemical composition of densified biomass fuels with regards to their combustion behaviour. Biomass and Bioenergy 2004;27: 653-69. 